\title{
Nano-Magnetic $\mathrm{Fe}_{3} \mathrm{O}_{4} / \mathrm{TiO}_{2}$ Composite : an Efficient Photocatalyst for 2,4 -Dichlorophenol Degradation Under Visible Light
}

\author{
M. Mehdipour $^{\text {a }}$, Gh. Khayati* a, A. Ebrahimian Pirbazari ${ }^{\mathrm{b}}$ \\ a Technical Faculty, University of Guilan, Rasht, 416353756, Iran, mona.mhdpr@gmail.com, khayati@guilan.ac.ir \\ ${ }^{\mathrm{b}}$ Fouman Faculty of Engineering, College of Engineering, University of Tehran, Fouman, 43516-66456, Iran, \\ aebrahimian@ut.ac.ir
}

\begin{abstract}
In this work, pure $\mathrm{TiO}_{2}$ and nano-magnetic of $\mathrm{Fe}_{3} \mathrm{O}_{4} / \mathrm{TiO}_{2}$ were synthesized for degradation of 2,4dichlorophenol (2, 4-DCP) as an organic pollutant. A range of analytical techniques including XRD, DRS, FESEM, and VSM were employed to reveal the crystal structure, morphology and property of the nanocomposite. The XRD results showed the prepared samples including $100 \%$ anatase phase. We obtained the band gap energy 2.9 and $2.8 \mathrm{eV}$ for pure $\mathrm{TiO}_{2}$ and $\mathrm{Fe}_{3} \mathrm{O}_{4} / \mathrm{TiO}_{2}$ respectively. VSM results demonstrate that easy, fast separation and redispersion of $\mathrm{Fe}_{3} \mathrm{O}_{4} / \mathrm{TiO}_{2}$ sample can be realized. We obtained $62 \%$ and $31 \%$ degradation of 2,4-DCP in the presence of $\mathrm{Fe}_{3} \mathrm{O}_{4} / \mathrm{TiO}_{2}$ and pure $\mathrm{TiO}_{2}$ under visible light respectively.
\end{abstract}

Keywords: Nano-Magnetic; $\mathrm{TiO}_{2} ; \mathrm{Fe}_{3} \mathrm{O}_{4}$; Degradation; 2,4-Dicholorophenol

\section{Introduction}

Titanium dioxide $\left(\mathrm{TiO}_{2}\right)$ is one of the photocatalysts that has been used to degrade organic pollutants. In practical application, there is a problem that needs to be resolved for the $\mathrm{TiO}_{2}$ photocatalyst. However, when $\mathrm{TiO}_{2}$ particles are dispersed into waste water, they are apt to be lost and difficult to be re-collected. To resolve this problem, photoactive $\mathrm{TiO}_{2}$ particles are coated onto magnetic cores [1]. To enhance the re-collecting ability of the composite photocatalyst, a magnetic material with strong magnetization, such as $\mathrm{Fe}_{3} \mathrm{O}_{4}$, should be exploited as the magnetic core [2].

In this study, $\left(\mathrm{TiO}_{2}\right)$ and nano-magnetic $\left(\mathrm{Fe}_{3} \mathrm{O}_{4} / \mathrm{TiO}_{2}\right)$ composites were synthesized by sol-gel method. The synthesized samples were identified with various techniques such as XRD, DRS, FESEM and VSM, and eventually photocatalysts were used for photocatalytic degradation of 2,4-DCP as an organic pollutants under visible light.

\section{Materials and Method}

$\mathrm{FeCl}_{3} \cdot 6 \mathrm{H}_{2} \mathrm{O}$ (Merck No. 103943), $\mathrm{FeSO}_{4} \cdot 7 \mathrm{H}_{2} \mathrm{O}$ (Merck No. 103965) were used for synthesis of $\mathrm{Fe}_{3} \mathrm{O}_{4}$ nanoparticles (NPs). Titanium isopropoxide (TIP) (Merck No. 8.21895), anhydrous ethanol, ammonia, and Highpurity 2, 4-DCP, 98\%, (Merck No. 803774) were used as a probe molecule for photocatalytic tests were purchased from Merck Company.

We synthesized $\left(\mathrm{Fe}_{3} \mathrm{O}_{4}\right)$ nanoparticles by chemical precipitation technique according to mentioned procedure in reference [3] and for synthesis of $\left(\mathrm{TiO}_{2}\right)$ and $\left(\mathrm{Fe}_{3} \mathrm{O}_{4} / \mathrm{TiO}_{2}\right)$, the method reported in reference [4] and reference [5], respectively was used with some modifications.

The XRD patterns were recorded on a Siemens, D5000 (Germany). The morphology of the prepared samples were characterized by using scanning electron microscope (FESEM) (Vegall-Tescan Company). The diffuse reflectance UV-Vis spectra (DRS) of the samples were recorded by an Ava Spec-2048TEC spectrometer. All the magnetic measurements have been done by VSM system which is made of Meghnatis Daghigh Kavir,(MDK), Company, Kashan I.R.Iran.

The photocatalytic activity of $\mathrm{TiO}_{2}$ and $\mathrm{Fe}_{3} \mathrm{O}_{4} / \mathrm{TiO}_{2}$ samples were evaluated by degradation of 2,4-DCP under visible-light which was used by (Halogen, ECO OSRAM, $500 \mathrm{~W}$ ) lamp. The degradation of 2,4-DCP was monitored by Rayleigh UV-2601 UV/VIS spectrophotometer $\left(\lambda_{\max }=\right.$ $227 \mathrm{~nm})$.

\section{Results and Discussion}

\section{X-RAY Diffraction Analyses}

Fig. 1 shows the XRD patterns of the pure $\mathrm{TiO}_{2}$ and nano-magnetic composite. All the observed diffractions are related to the anatase phase according to diffraction peaks at the reference[6], $2 \theta=25.4^{\circ}, 38.0^{\circ}, 48.0^{\circ}, 54.7^{\circ}$ and $63.1 \circ$ were all designated to anatase crystal phase of $\mathrm{TiO}_{2}$ [6], In addition peaks which showed with an asterisk (*) are related to diffractions of $\mathrm{Fe}_{3} \mathrm{O}_{4}[7]$. We also calculated the average crystal size of $\mathrm{TiO}_{2}$ and $\mathrm{Fe}_{3} \mathrm{O}_{4} / \mathrm{TiO}_{2}$ in the range of (7.12-8.89 $\mathrm{nm})$, respectively. 


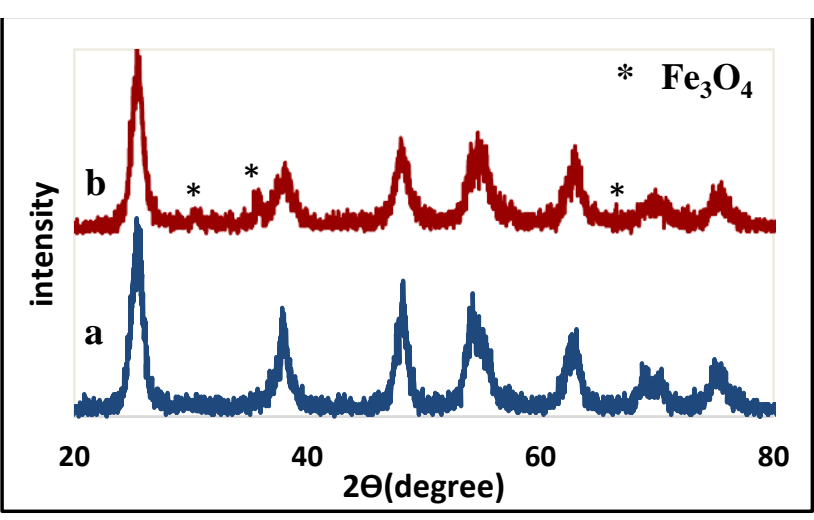

Fig.1: XRD patterns of a) $\mathrm{TiO}_{2}$, b) $\mathrm{Fe}_{3} \mathrm{O}_{4} / \mathrm{TiO}_{2}$

\section{FESEM Analysis}

Fig. 2 shows the FESEM images of $\mathrm{TiO}_{2}$, and $\mathrm{Fe}_{3} \mathrm{O}_{4} / \mathrm{TiO}_{2}$ nanocomposites. It is noteworthy that in the FESEM image of nano-magnetic composite, there are a number of particles dispersed on the outer surface of the $\mathrm{Fe}_{3} \mathrm{O}_{4}$ nanoparticles.
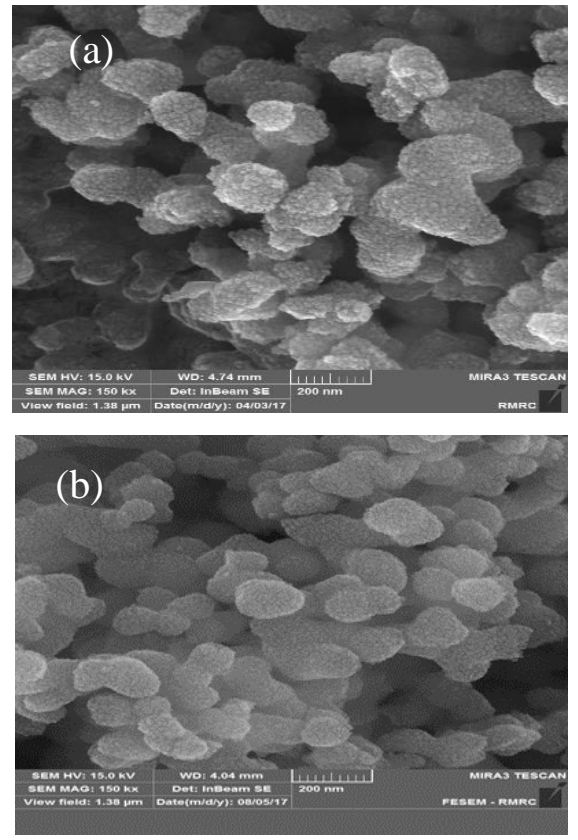

Fig.2: FESEM images of a) $\mathrm{TiO}_{2}$ and b) $\mathrm{Fe}_{3} \mathrm{O}_{4} / \mathrm{TiO}_{2}$.

\section{DRS Analysis}

Diffuse reflectance spectra of the prepared samples are shown in Fig.3 the DR spectra of $\mathrm{TiO}_{2}$ consist of a broad intense absorption around $404 \mathrm{~nm}$, due to charge-transfer from the valence band formed by $2 p$ orbitals of the oxide anions to the conduction band formed by $3 \mathrm{~d} \mathrm{t}_{2 \mathrm{~g}}$ orbitals of the $\mathrm{Ti}^{4+}$ cations[8]. The DR spectra of $\mathrm{Fe}_{3} \mathrm{O}_{4} / \mathrm{TiO}_{2}$ exhibits an enhanced light absorption than $\mathrm{TiO}_{2}$ in the range of 400$800 \mathrm{~nm}$. This result suggests that presence of $\mathrm{Fe}_{3} \mathrm{O}_{4}$ can enhance the visible light absorption which may improve the photocatalytic activity.

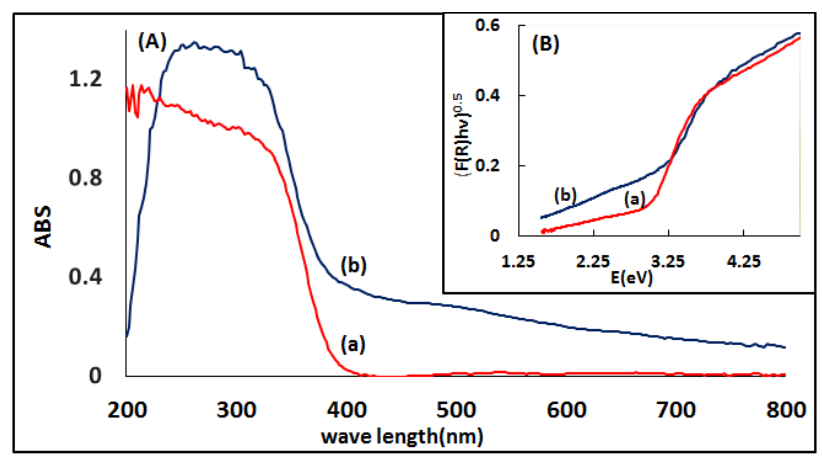

Fig.3: A) Diffuse reflectance spectra, B) Kubelka-Munk plots for the band gap energy calculation of a) $\mathrm{TiO}_{2}$ and b) $\mathrm{Fe}_{3} \mathrm{O}_{4} / \mathrm{TiO}_{2}$.

According to below equation, we calculated the band gap energy from the DR spectra for the prepared samples [9].

$[F(R) h v]^{0.5}=A\left(h v-E_{g}\right)$

Where A is constant, $F(R)$ is the Kubelka-Munk function and $\mathrm{Eg}$ is the band gap. The calculated band gap energy of pure $\mathrm{TiO}_{2}$ and $\mathrm{Fe}_{3} \mathrm{O}_{4} / \mathrm{TiO}_{2}$ were 2.90 and 2.80 respectively. The band gap of the binary nano-magnetic composites decreased slightly compared with $\mathrm{TiO}_{2}$.

\section{VSM Analysis}

The magnetic properties of nano-magnetic composite was measured by VSM at room temperature. The hysteresis loops of the powered samples are shown in Fig. 4. It is worth nothing that the $\mathrm{Ms}$ value of the $\mathrm{Fe}_{3} \mathrm{O}_{4}$ nanoparticles is significantly higher than $\mathrm{Fe}_{3} \mathrm{O}_{4} / \mathrm{TiO}_{2}$ sample, which is because the $\mathrm{Fe}_{3} \mathrm{O}_{4}$ nanoparticles are covered with an anatase $\mathrm{TiO}_{2}$ layer in the $\mathrm{Fe}_{3} \mathrm{O}_{4} / \mathrm{TiO}_{2}$ sample. [5]

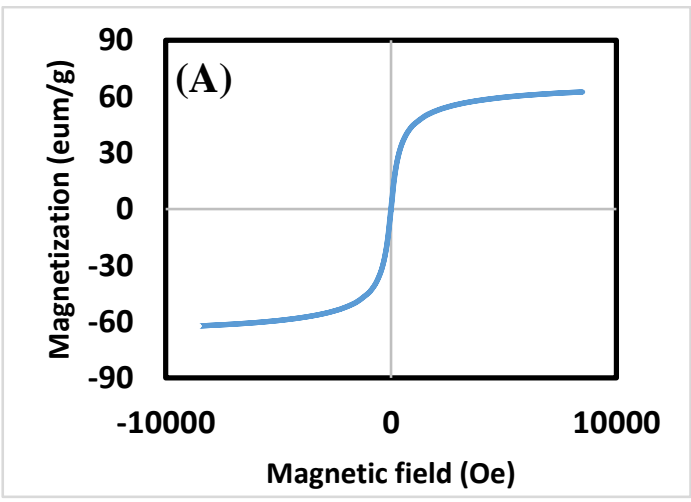




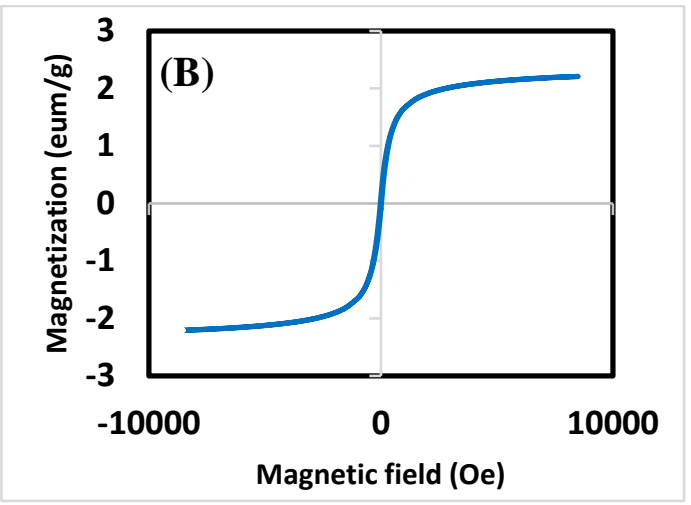

Fig.4: Comparison of hysteresis curves of A) $\mathrm{Fe}_{3} \mathrm{O}_{4}$ and B) $\mathrm{Fe}_{3} \mathrm{O}_{4} / \mathrm{TiO}_{2}$.

\section{Photocatalytic Degradation of 2,4-DCP}

The performance of the synthesized samples was studied for photocatalytic treatment of synethic wastewater containing 2,4-DCP at room temperature, under visible light (Fig. 5). The experimental results demonstrated that nano-magnetic composite showed a higher activity for treatment of 2,4-DCP (62\%) under visible light compared to pure $\mathrm{TiO}_{2}$. It shows that $\mathrm{Fe}_{3} \mathrm{O}_{4}$ has been proved to be a good promoter to hybridize with $\mathrm{TiO}_{2}$.

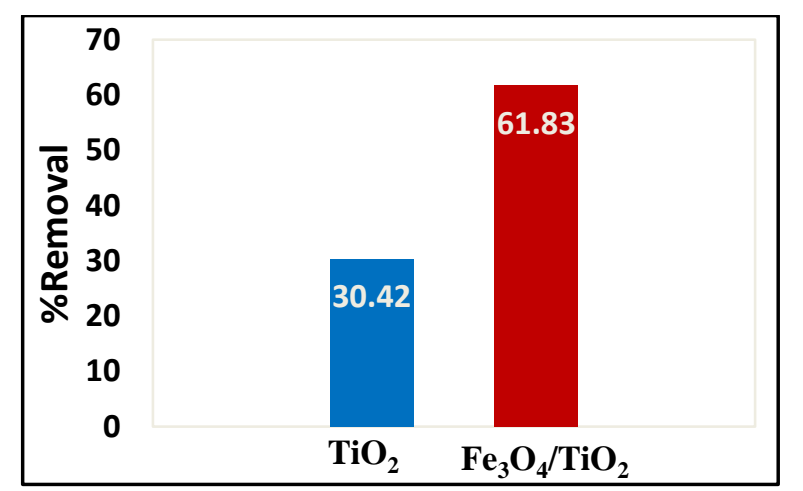

Fig.5: Photocatalytic degradation of 2, 4-DCP in the presence of the prepared samples under visible light. Initial concentration of 2, 4-DCP, $40 \mathrm{mg} / \mathrm{L}$; volume, $100 \mathrm{~mL}$; catalyst dosage: $10 \mathrm{mg}$.

\section{Conclusion}

Pure $\mathrm{TiO}_{2}$ and nano-magnetic $\mathrm{Fe}_{3} \mathrm{O}_{4} / \mathrm{TiO}_{2}$ composite were synthesized by sol-gel method for degradation of 2 , 4-dichlorophenol and characterized by several techniques successfully. From among all of the samples only anatase phase was confirmed from the XRD results. FESEM and DRS results confirmed $\mathrm{Fe}_{3} \mathrm{O}_{4}$ presence in the nanomagnetic sample by decreasing band gap. Furthermore VSM result confirmed magnetization of $\mathrm{Fe}_{3} \mathrm{O}_{4} / \mathrm{TiO}_{2}$ sample. Nano-magnetic $\mathrm{Fe}_{3} \mathrm{O}_{4} / \mathrm{TiO}_{2}$ composite exhibited the higher photocatalytic activity by $62 \%$ degradation compared with $\mathrm{TiO}_{2}$ (31\% degradation), under visible light after $180 \mathrm{~min}$ of irradiation.

\section{Acknowledgment}

The authors wish to acknowledge the financial support of the University of Guilan and University of Tehran for supporting of this research.

\section{References}

[1] Lee S.W., Drwiega J., Wu C.Y., Mazyck D., and Sigmund W.M., "Anatase $\mathrm{TiO}_{2}$ nanoparticle coating on barium ferrite using titanium bis-ammonium lactate dihydroxide and its use as a magnetic photocatalyst", Chem. Mater., 2004, 16: 1160.

[2] L. Yuxiang, Zh. Mei, G. Min, W. Xidong, "Preparation and properties of a nano $\mathrm{TiO}_{2} / \mathrm{Fe}_{3} \mathrm{O}_{4}$ composite superparamag-netic photocatalyst", Rare Metals Vol.28,No.5, Oct 2009,P.423.

[3] A. E. Pirbazari, E. Saberikhah, and S. H. Kozani, " $\mathrm{Fe}_{3} \mathrm{O}_{4}$-wheat straw: preparation, characterization and its application for methylene blue adsorption," Water Resources and Industry, vol. 7, pp. 23-37, 2014.

[4] C. H. Aguilar, T. Pandiyan, J. Arenas-Alatorre, and N. Singh, "Oxidation of phenols by $\mathrm{TiO}_{2} / \mathrm{Fe}_{3} \mathrm{O}_{4} \mathrm{M}(\mathrm{M}=\mathrm{Ag}$ or $\mathrm{Au}$ ) hybrid composites under visible light," Separation and Purification Technology, vol. 149, pp. 265-278, 2015.

[5] N. Esmaeili, A. Ebrahiman Pirbazari, Z. Khodaee, "Visiblelight active and magnetically recyclable Agcoated $\mathrm{Fe}_{3} \mathrm{O}_{4} / \mathrm{TiO}_{2}$ nanocomposites for efficient photocatalytic oxidation of 2,4-dichlorophenol", Desalination and Water Treatment, in press.

[6] Zh. Zhang, Y. Xu, X. Ma, F. Li,D. Liu, Zh. Chen "Microwave degradation of methyl orange dye in aqueous solution in the presence of nano- $\mathrm{TiO}_{2}$-supported activated carbon (supported- $\mathrm{TiO}_{2} / \mathrm{AC} / \mathrm{MW}$ )", Hazardous Materials 209-210(2012)271-277.

[7] M.Hadipour Bahambara, A. Ebrahimian Pirbazaria, N.Gilani, "Photocatalytic removal of methyl orange from synthetic wastewater by ternary $\mathrm{Fe}_{3} \mathrm{O}_{4} / \mathrm{TiO}_{2} / \mathrm{MWCNTs}$ nanocomposites under visible light, Desalination and water treatment", 89(2017)181-188.

[8] A.Ebrahimian, P.Monazzam and B.Fakhari.,"

$\mathrm{Co} / \mathrm{TiO}_{2}$ nanoparticles: preparation, characterization and its application for photocatalytic degradation of methylene blue", Desalination and Water Treatment, 63 (2017) 283-292.

[9] S. Kumar, S. Khanchandani, M. Thirumal, and A. K. Ganguli, "Achieving enhanced visible-light-driven photocatalysis using type-II $\mathrm{NaNbO}_{3} / \mathrm{CdS}$ core/shell heterostructures", ACS applied materials \& interfaces, vol. 6, no. 15, pp. 13221-13233, 2014. 